\title{
Crohn's disease of the stomach and duodenum
}

J. F. FIELDING, D. K. M. TOYE, D. C. BETON, AND W. T. COOKE

The Nutritional and Intestinal Unit and the Department of Radiology, The General Hospital, Birmingham

SUMMAR Y Clinical and radiological abnormalities in 12 patients with gastroduodenal involvement were encountered amongst 300 patients followed by one of us between 1944 and 1969 . Symptoms of dyspepsia were relatively mild and obstructive symptoms when present were readily relieved by bypass surgery. The patients have been followed for a mean of $9 \cdot 7$ years (range 1-20); two have died of other causes but the remaining 10 are well.

In 1950, Comfort, Weber, Baggenstoss, and Kiely in a report on five patients established that nonspecific granulomatous inflammation of the stomach and the duodenum was the same condition as regional enteritis affecting other parts of the small intestine. Roberts and Hamilton (1966) found that only 34 patients had been reported by 1962. By 1967, approximately 62 patients had been recorded but little information is available from the reports as to the prognosis and clinical course. This paper considers the significance of involvement of stomach and duodenum in Crohn's disease from the experience of 12 patients encountered amongst 300 followed by one of us between 1944 and 1969.

\section{Clinical Material}

There were six men and six women, including a brother and sister. At the time of diagnosis they varied in age between 17 and 60 years, six being under 25. In four, the lesion developed after the occurrence of the disorder elsewhere in the intestinal tract; in the remaining eight patients it was present at the time of the initial diagnosis of Crohn's disease. Histological demonstrations of granulomatous lesions were made in four patients, in nine the macroscopic appearances at operation were thought characteristic, and in 11 radiological appearances indicated this diagnosis. All but one had evidence of Crohn's disease elsewhere at some time during the period of observation. The remaining patient (case 2) had a gastric lesion with positive histological findings.

\section{Symptoms}

Symptoms had been present before diagnosis for an average period of 16 months, varying from three to 55 months. Pain was rarely severe and was present in 11 patients. It was epigastric in location and did not radiate. Usually, relief was obtained from antacid therapy. Nausea and vomiting occurred in nine patients. Typically, this took place late at night or in the early hours of the morning and led to relief of symptoms. Episodic diarrhoea stressed by Comfort et al (1950) occurred in seven of the 12 patients. It was not a prominent symptom but it was not possible to determine whether it was due to involvement of the duodenum or of other areas of affected gut. All but one patient had lost weight. One patient (case 12) had none of these symptoms but presented with melaena following the ingestion of aspirin compounds. 


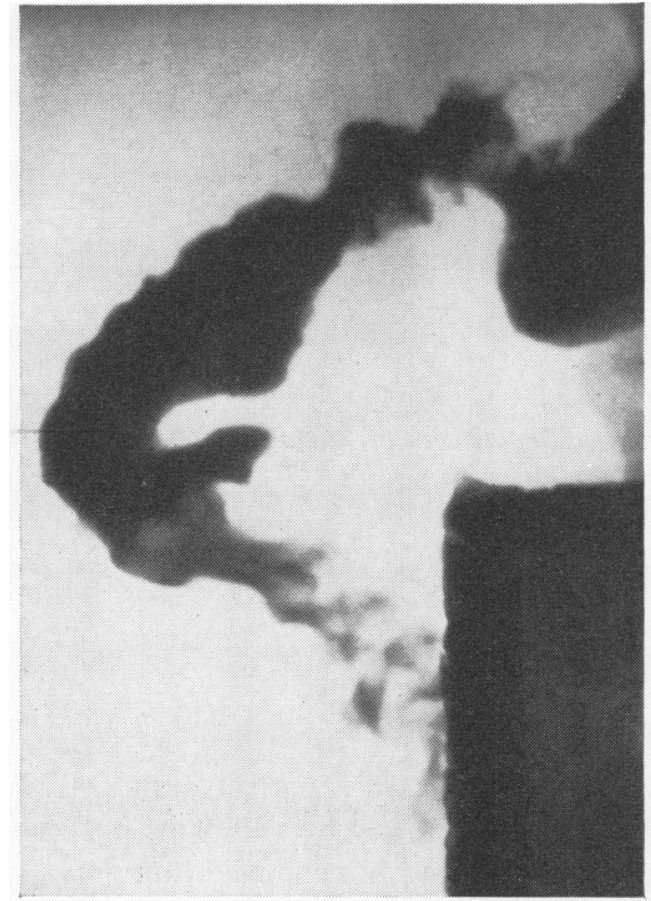

Fig. 1a.

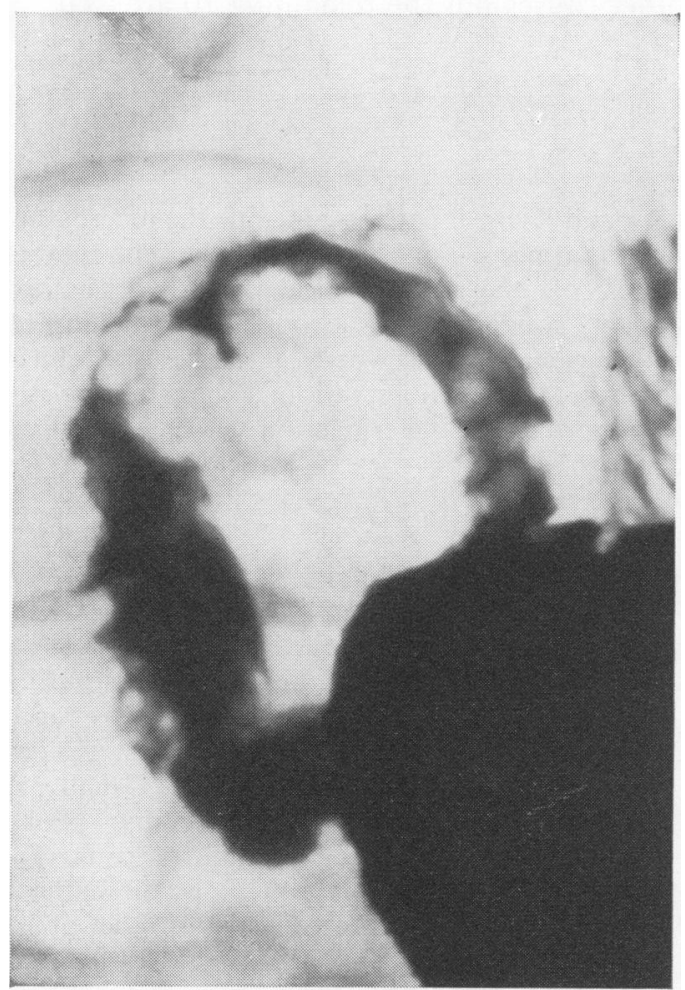

Fig. 1b.

Fig. 1. Irregular cobblestone mucosa stretched from the tip of the antrum, through the duodenal loop to the third portion. When filled (Fig. 1a) the restriction of the duodenal lumen is shown and a deep fissure arises from the lesser curvature of the duodenal cap. When partly filled (Fig. 1b) fine fissures are well seen in the supra-ampullary segment of the duodenum.

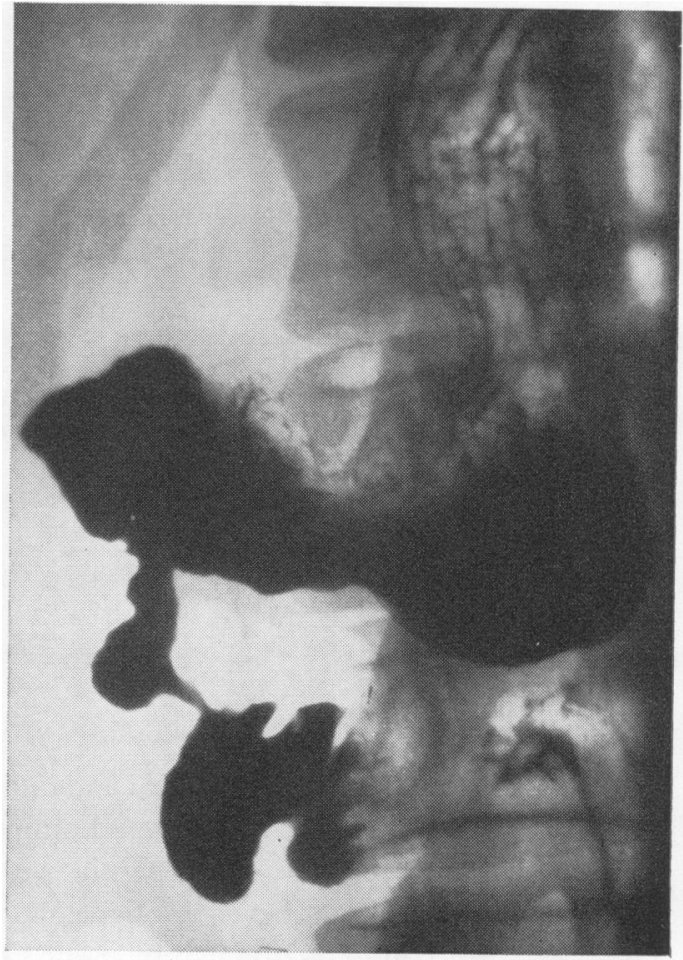

Fig. 2a.

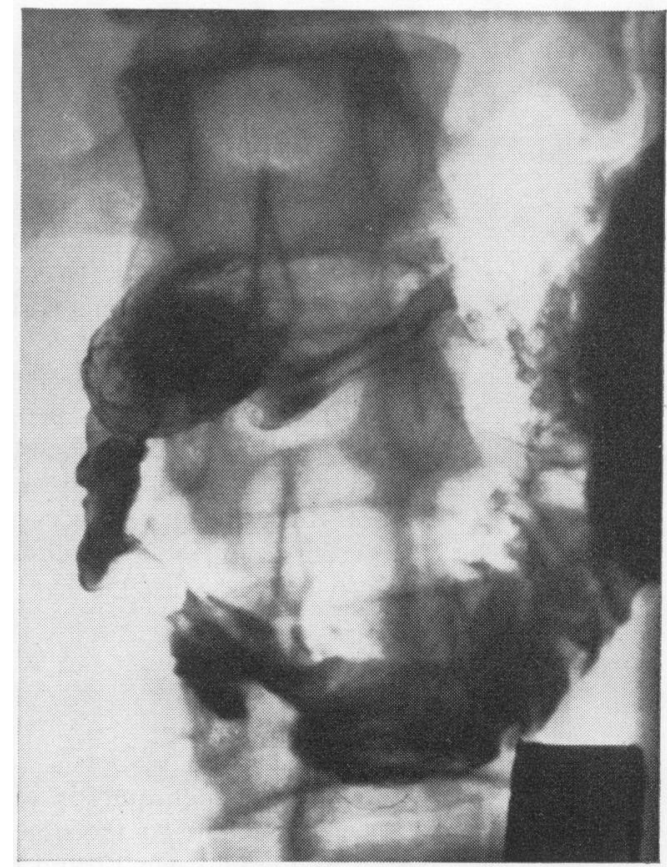

Fig. 2b.

Fig. 2a and $\mathrm{b}$ The second part of the duodenum is eccentrically narrowed with a very narrow segment leading to a dilated flexible portion in the third part. The third part narrows then widens and coarse mucosa is seen running horizontally to the fourth part of the duodenum. There the mucosa remains coarse but the folds become transverse. 


\section{Radiological Findings}

Of the patients in this series, good radiographs were available for review in eight patients. Characteristic changes of Crohn's disease were seen in cases 4, 7, 8, 11, and 12 (Figs. 1 and 2). The antrum was involved in four patients; in two (cases 8 and 9) the pyloric antrum was cone shaped (Fig. 3). In cases 11 and 12, the mucosa was cobblestoned in the tip of the antrum with contiguous disease in the duodenum. In a further patient (case 1) there was such pyloric delay that the duodenal lesion, confirmed at operation, could not be displayed.

In the duodenum, mucosal changes varied from slight coarsening to an overt cobblestone pattern with fissures. Changes in the wall varied from short, single, or multiple strictures to long segments of eccentric and concentric narrowing. When multiple narrowed segments were present, the intervening portions showed normal or excessive distensibility. In cases 4 and 7 , fine linear radioluscencies or shelf-like but incomplete diaphragms were seen in the first part of the duodenum. Mucosal scarring indicative of peptic ulceration was not seen in any patient.

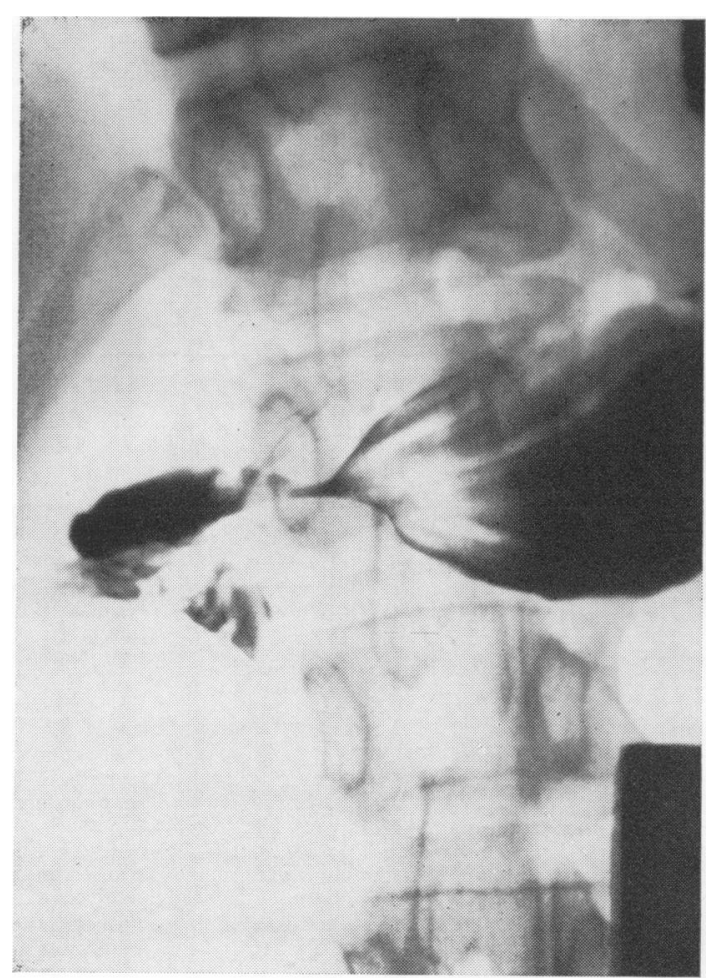

Fig. 3. This cone-shaped narrowing of the tip of the pyloric antrum was seen in filled and in air-contrast films. The slight notch on the greater curvature was also constantly observed.
In cases 5, 7, and 9 there was radiological evidence of improvement; cases 5 and 9 had had positive radiological reports 14 and 15 years previously with confirmation of the lesion at operation by surgeons experienced in the surgery of Crohn's disease. In case 5, all that can be demonstrated now is slight coarsening of the duodenal mucosa and a small stricture just distal to the ampulla of Vater (Fig. 4). Case 9 showed multiple ring stenoses with pseudo diverticulum formation and some straightening of the intervening mucosal pattern (Fig. 5). In the third patient (case 7) there was considerably less mucosal thickening and less narrowing than in the film taken two years previously.

\section{Clinical Course and Treatment}

Twelve patients have been followed for periods varying from one to 20 years (mean $9 \cdot 7$ years). Two patients have died, case 3 of myocardial infarction and case 6 of cancer. The present status of the remaining 10 patients is listed in the Table.

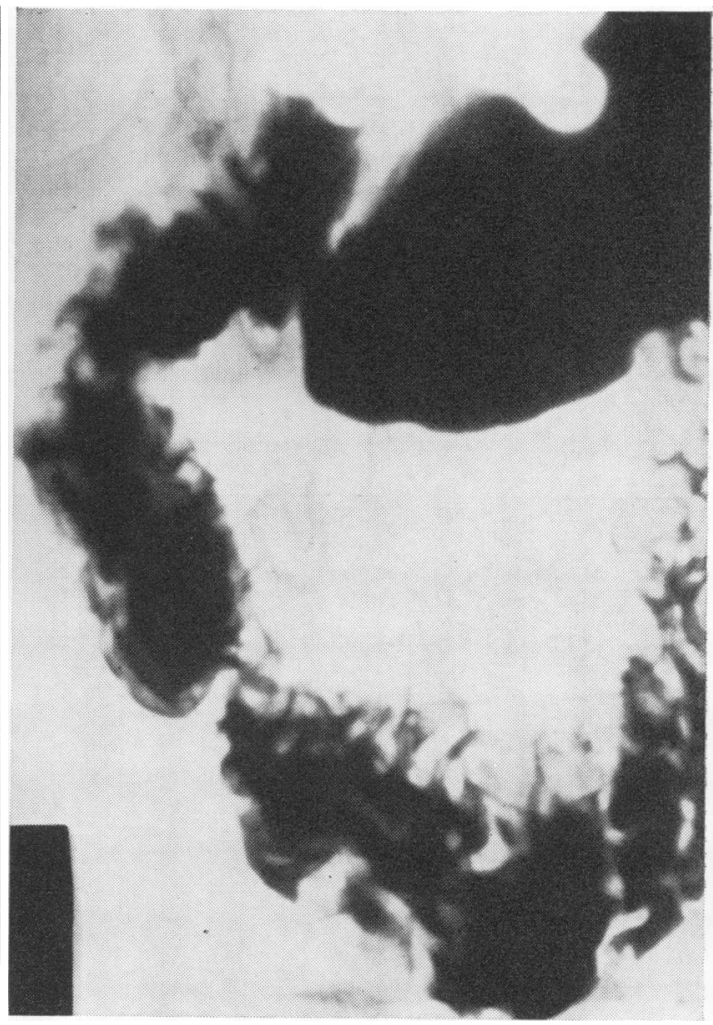

Fig. 4. The duodenal mucosa is generally coarser than usual and there is a constant narrowing of the lumen beyond the region of the ampulla of Vater. 


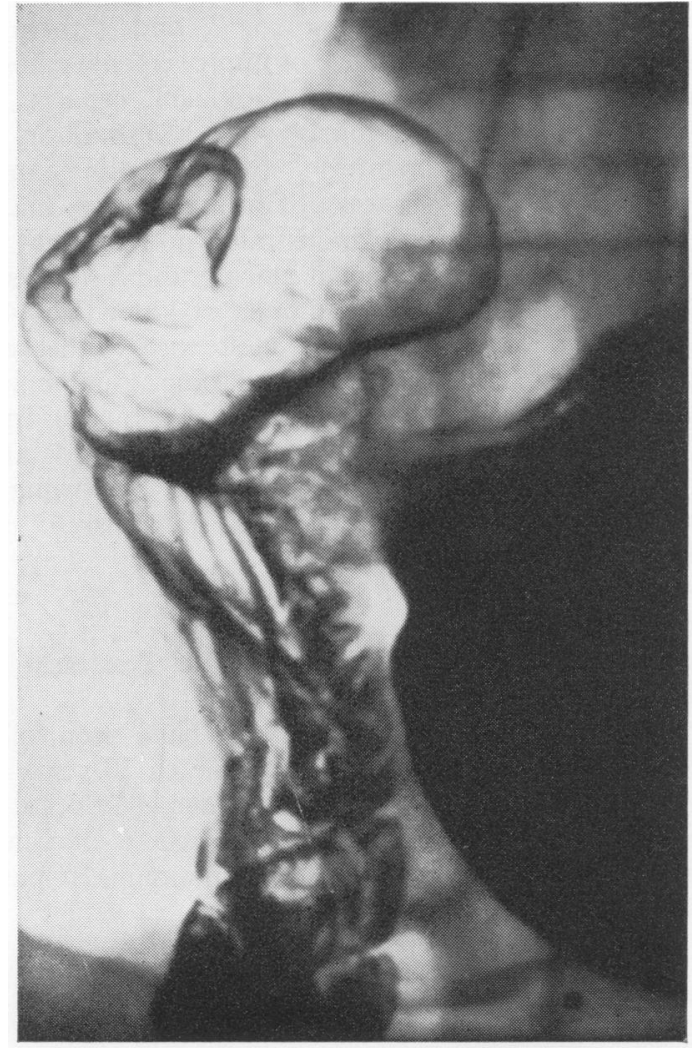

Fig. 5a.

Fig. 5 Air contrast films showing (a) longitudinal mucosal folds and (b) multiple pseudodiverticula on the medial wall of the descending duodenum resulting from the multiple ring stenoses.

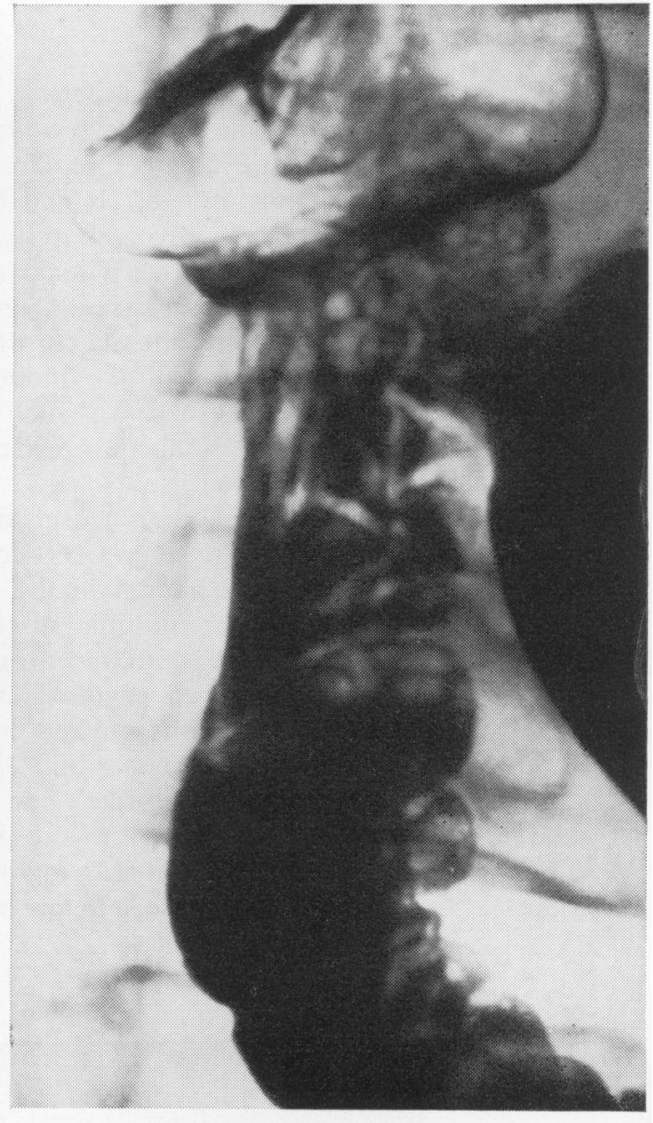

Fig. 5b.

\begin{tabular}{|c|c|c|c|c|c|c|c|c|c|c|}
\hline \multirow{2}{*}{$\begin{array}{l}\text { Case } \\
\text { No. }\end{array}$} & \multirow[t]{2}{*}{ Sex } & \multirow[t]{2}{*}{ Age } & \multirow[t]{2}{*}{ Site } & \multicolumn{2}{|c|}{ Appearance } & \multicolumn{2}{|c|}{ Follow Up (yr) } & \multirow{2}{*}{$\begin{array}{l}\text { Other Sites Treatment } \\
\text { Involved }\end{array}$} & \multirow[t]{2}{*}{ Other Events } & \multirow[t]{2}{*}{ Present State } \\
\hline & & & & $\begin{array}{l}\text { At } \\
\text { Surgery }\end{array}$ & $\begin{array}{l}\text { At } \\
\text { Radiology }\end{array}$ & $\begin{array}{l}\text { Gastro- } \\
\text { duodenal } \\
\text { Ulcer }\end{array}$ & $\begin{array}{l}\text { Crohn's } \\
\text { Disease }\end{array}$ & & & \\
\hline
\end{tabular}

\begin{tabular}{|c|c|c|c|c|c|c|c|c|c|c|c|}
\hline 1 & $\mathbf{M}$ & 19 & G.duodenum ${ }^{1}$ & + & + & 11 & 11 & Colon & Gastroenterostomy & $\begin{array}{l}\text { Panproctectomy } \\
3 \text { years later }\end{array}$ & Symptom fre \\
\hline 2 & $\mathbf{M}$ & 60 & G.duodenum ${ }^{1}$ & + & + & 20 & 20 & - & Billroth I & & Symptom fre \\
\hline 3 & $\mathbf{M}$ & 38 & Duodenum & + & + & 10 & 10 & Jejunum & Gastroenterostomy & $\begin{array}{l}\text { Died; myocardial } \\
\text { infarct }\end{array}$ & - \\
\hline 4 & $\mathbf{M}$ & 53 & Duodenum & & + & 1 & 33 & $\begin{array}{l}\text { Jejunum, } \\
\text { ileum }\end{array}$ & - & Four resections & $\begin{array}{l}\text { Occasional } \\
\text { dyspepsia }\end{array}$ \\
\hline 5 & $\mathbf{M}$ & 17 & Duodenum & + & + & 15 & 15 & $\begin{array}{l}\text { Jejunum, } \\
\text { ileum }\end{array}$ & ACTH & Three resections & Symptom fre \\
\hline 6 & $\mathbf{M}$ & 41 & Duodenum $^{1}$ & + & + & 7 & 8 & $\begin{array}{l}\text { Jejunum, } \\
\text { ileum }\end{array}$ & ACTH & $\begin{array}{l}\text { Died: cancer of } \\
\text { ampulla of Vater } \\
\text { six years later }\end{array}$ & - \\
\hline 7 & $\mathbf{F}$ & 21 & Duodenum & + & + & 3 & 3 & $\begin{array}{l}\text { Jejunum, } \\
\text { ileum }\end{array}$ & ACTH & - & $\begin{array}{l}\text { Occasional } \\
\text { colic }\end{array}$ \\
\hline 8 & $\mathbf{F}$ & 50 & G.duodenum ${ }^{1}$ & + & + & 4 & 22 & Colon & $\begin{array}{l}\text { Vagotomy and } \\
\text { pyloroplasty }\end{array}$ & $\begin{array}{l}\text { Antrectomy three } \\
\text { years later }\end{array}$ & $\begin{array}{l}\text { Occasional } \\
\text { colic }\end{array}$ \\
\hline 9 & $\mathbf{F}$ & 21 & G.duodenum & + & & 14 & 14 & Ileum & Gastroenterostomy & $\begin{array}{l}\text { Ileal resection } 13 \\
\text { years later }\end{array}$ & Symptom fre \\
\hline 10 & $\mathbf{F}$ & 22 & Duodenum & & + & 15 & 15 & Ileum & $\bar{n}$ & & Symptom fre \\
\hline 11 & $\mathbf{F}$ & 23 & Duodenum & & + & 15 & 28 & $\begin{array}{l}\text { Jejunum, } \\
\text { ileum }\end{array}$ & Duodenojejunostomy & Two resections & $\begin{array}{l}\text { Occasional } \\
\text { colic }\end{array}$ \\
\hline 12 & $\mathbf{F}$ & 46 & Duodenum & & + & 1 & 1 & Ileum & - & One resection & Symptom fre \\
\hline
\end{tabular}


Operations were carried out on six patients (cases 1, 2, 3, 8, 9, and 11) for pain and obstructive symptoms. In four, bypass procedures were performed and in one a Billroth I gastrectomy. These five patients had excellent results, becoming free of symptoms with no further trouble during a follow-up period varying from 10 to 20 years (mean 14 years). The sixth patient (case 8) underwent pyloroplasty and vagotomy but obtained little relief so that three years later antrectomy and gastroduodenostomy were necessary to relieve the symptoms.

Three patients have had no definitive therapy. Case 4, who has had recurrent involvement of the intestinal tract over the past 30 years and radiological evidence of severe duodenal narrowing for two years, has occasional epigastric pain. Even so, at the age of 53 he is able to hunt with fox hounds three times a week and go skiing in season. Case 10 , sister of case 5 , has had radiological evidence of duodenal involvement for 15 years and is at present free of symptoms. The third patient, case 12 , has had no symptoms beyond the initial melaena which brought about the discovery of the gastroduodenal Crohn's disease.

The remaining three patients have been treated with corticosteroids or ACTH mainly on account of involvement of other areas of the small intestine. Case 5, who has had extensive jejunoileal lesions, has had prednisone therapy for the past 15 years and undergone three resections of parts of the small intestine. $\mathrm{He}$ is well and symptom free. Case 6 was only partly controlled by oral prednisone and after six years gastrojejunostomy was carried out. He died a year later with carcinoma of the ampulla of Vater. Case 7 has been treated for three years with ACTH for diffuse jejuno-ileal involvement in addition to the gastroduodenal involvement.

\section{Discussion}

Comfort and his colleagues (1950) listed the symptoms of gastroduodenal Crohn's disease, noting a continuous or intermittent upper abdominal pain, made worse by food, systemic upset with fever, and loss of weight, diarrhoea, and lastly by a progressive stenosing lesion in the duodenum. In the patients reported in this series, the symptoms were relatively mild and when related to food were relieved by antacid therapy; this was also noted by Jones, Dooley, and Schoenfield (1966). Obstructive symptoms at some time during the course of the disorder were common and were present in two thirds of our patients and in six out of eight patients reported by Jones et al (1966).

In differential diagnosis of the condition, simple peptic ulceration poses the biggest problem. Jones et al (1966) considered that when the peptic ulcer type of epigastric distress and the retention type of vomiting are associated with diarrhoea then the diagnosis of regional enteritis with involvement of the duodenum should be strongly considered. Durrance (1962) noted that '... if a typical string sign is demonstrated (in the duodenum) with skip areas of involvement or if distal ileal involvement is noted, the diagnosis is established with certainty'. Roberts and Hamilton (1966) noted radiological evidence of peptic ulceration in two patients but, as in our two patients (cases 2 and 3), the ulcer could not be demonstrated at surgery in one, nor confirmed histologically in the other.

In this series of 300 patients with Crohn's disease, the incidence of gastroduodenal involvement was $4 \%$. With the exception of Berk(1956), who noted three so affected amongst 16 patients, other reports give a lower incidence. Marshak and Wolf (1955) commented upon four amongst 750 patients, Durrance (1962) noted three amongst 600 patients, whilst Jones et al (1966) found only eight so affected out of 500 patients with regional enteritis seen at the Mayo Clinic between 1950 and 1964.

In addition to these 12 patients with gastroduodenal Crohn's disease, there were 24 with peptic ulceration (Fielding and Cooke, 1970). Clearly the symptoms in these patients were very similar to those encountered in gastroduodenal Crohn's disease though pain was a more prominent feature than obstruction. We have no evidence that peptic ulceration could initiate the onset of gastroduodenal Crohn's disease. Peptic ulceration followed the usual course in our patients with persistence of scarring when in the duodenum necessitating operation in nine patients.

With stress placed on loss of weight and the features of malabsorption, it is not surprising that a somewhat pessimistic outlook has arisen. Two out of five patients reported by Comfort et al (1950) and four out of 17 of those noted by Richman, Zeifer, Winkelstein, Kirschner, and Stenhardt (1955) died within a short time of diagnosis. Little has been written on the outcome of this involvement. Comfort et al (1950) reported a man who was well for 15 years after a by-pass operation and Berk (1956) recorded a patient remaining well for two and a half years after a similar operation. In this series, with follow up averaging nearly 10 years, permanent disability has been surprisingly rare. Bypass operations have been successful but pyloroplasty and vagotomy was not satisfactory in the one patient in whom this operation was performed whilst in three patients no specific therapy has so far been necessary. No conclusion can be made concerning the efficacy of steroid therapy.

To sum up, in our experience, the course of gastroduodenal Crohn's disease has been associated with relatively mild dyspepsia. Obstructive symptoms when present have been readily relieved by bypass operations. 


\section{References}

Berk, M. (1956). Regional enteritis involving the duodenum. Gastroenterology, 30, 508-516.

Comfort, M. W., Weber, H. M., Baggenstoss, A. H., and Kiely, W. F. (1950). Nonspecified granulomatous inflammation of the stomach and duodenum; its relation to regional enteritis Amer. J. med. Sci., 220, 616-632.

Durrance, F. Y. (1962) Regional enteritis of the duodenum. Amer. J. Roentgenol., 88, 658-661.

Fielding, J. F., and Cooke, W. T. (1970). Peptic ulceration in Crohn's disease (regional enteritis). Gut, 11, 998-1000.
Jones, G. W., Jr., Dooley, M. R., and Schoenfield, L. J. (1966). Regional enteritis with involvement of duodenum. Gastroenterology, 51, 1018-1022.

Marshak, R. H., and Wolf, B. S. (1955). Roentgen findings in regional enteritis. Amer. J. Roentgenol, 74, 1000-1014.

Richman, A., Zeifer, H. D., Winkelstein, A., Kirschner, P. A., and Steinhardt, R. D. (1955). Chronic nonspecific granulomatous inflammation of the stomach, duodenum and intestine. Gastroenterology, 29, 358-369.

Roberts, S. M., and Hamilton, W. W. (1966). Regional enteritis of $\overrightarrow{\overparen{D}}$ the duodenum. Radiology, 86, 881-885. 